\title{
La figura del mediador intercultural a les institucions escolars catalanes: perfils real i ideal segons els propis actors
}

\author{
Núria Llevot Calvet \\ Universitat de Lleida. Departament de Pedagogia i Psicologia \\ Complex La Caparrella, s/n. 25192 Lleida \\ nllevot@pip.udl.es
}

\section{Resum}

A Catalunya, en els darrers anys, han anat proliferant una sèrie de "professionals» que realitzen, amb més o menys adequació a la definició teòrica, la funció de mediadors interculturals. Primerament, es tractava de gitanos, però darrerament, fruit de l'increment de la presència d'infants d'origen immigrant a les escoles catalanes, s'ha vist créixer el nombre i el protagonisme dels estrangers pel reconeixement que se'ls ha donat des de l'Administració i des de les institucions. Els mediadors han intentat intervenir en qüestions com ara la participació dels pares d'origen minoritari, l'adaptació del currículum a la diversitat cultural, la negociació de conflictes culturals, la desescolarització, l'absentisme i l'abandonament escolar dels alumnes durant el període d'escolarització obligatòria, la traducció lingüística i la interpretació sociocultural, etc. Concretament, la nostra recerca ha consistit en vint-i-set entrevistes en profunditat a mediadors interculturals de tot Catalunya.

Paraules clau: mediadors interculturals, institucions escolars, famílies, gitanos, immigrants.

Resumen. La figura del mediador intercultural en las instituciones escolares catalanas: perfiles real e ideal según los propios actores

En Cataluña, en los últimos años, han ido proliferando una serie de "profesionales» que realizan, con más o menos adecuación a la definición teórica, la función de mediadores interculturales. En primera instancia, se trataba de gitanos, pero recientemente, fruto del incremento de la presencia de niños de origen inmigrante en las escuelas catalanas, se ha visto crecer el número y el protagonismo de los extranjeros por el reconocimiento que se les ha otorgado desde la Administración y las instituciones. Los mediadores han intentado intervenir en cuestiones como la participación de los padres de origen minoritario, la adaptación del currículo a la diversidad cultural, la negociación de conflictos culturales, la desescolarización, el absentismo y el abandono escolar de los alumnos durante el período de la escolarización obligatoria, la traducción lingüística y la interpretación sociocultural, etc. Concretamente, nuestra investigación ha consistido en veintisiete entrevistas en profundidad a mediadores interculturales de toda Cataluña.

Palabras clave: mediadores interculturales, instituciones escolares, familias, gitanos, inmigrantes. 
Abstract. The mediator's intercultural figure in the Catalan school institutions: real profile and ideal according to the own actors

In recent years in Catalonia, there has been a proliferation of a series of "professionals» who carry out, more or less in accordance with the theoretical definition, the function of intercultural mediators. At first, they were gypsies, however, recently, as a result of the increase in the presence of immigrant origin children in Catalan schools, the number and the role of foreigners has increased as a result of the recognition they have received from the administration and the institutions. The intercultural mediators have tried to intervene in questions such as the participation of parents of immigrant or minority origins in the schools, the adaptation of the curriculum to the cultural diversity, negotiation in cultural conflicts, enrolment in schools, absenteeism and abandoning of pupils during the compulsory schooling period, linguistic translation and socio-cultural interpretation, etc. This latter consisted of in-depth interviews with mediators, a total 27 , the empirical research work covered all Catalonia.

Key words: intercultural mediators, educational institutions, parents, gypsies, immigrant.

\section{Sumari}

1. Introducció: la mediació i els mediadors interculturals a Catalunya

2. Qui són els mediadors interculturals que actuen a Catalunya?

3. El perfil real i el perfil ideal
4. Reflexions finals

Bibliografia

\section{Introducció: la mediació i els mediadors interculturals a Catalunya}

L'experiència assolida al llarg d'aquests darrers anys en l'escolarització i la integració social dels alumnes en risc de marginació social ens indica quins són els problemes que es produeixen amb més freqüència i les vies de solució que han resultat més eficaces. Fins ara, el model d'intervenció predominant ha pivotat sobre el voluntariat, la bona voluntat d'alguns professionals, la iniciativa personal i col-lectiva d'algunes persones de les minories i la presència d'associacions i entitats no governamentals (Besalú, 2002). En general, s'han realitzat intervencions puntuals quan la comunicació ha estat quasi impossible o el conflicte ja s'ha produït. Sabem que l'escolarització de qualitat d'aquests alumnes no és un fet puntual ni poc significatiu, sinó que afecta un gran nombre de persones i requereix una intervenció consolidada i dilatada en el temps i una dedicació temporal considerable. Els processos d'integració són lents, perquè els canvis requerits impliquen noves actituds i mentalitats. A més, sempre seran més eficaces les polítiques preventives que les estrictament correctives. Per altra banda, hem pogut comprovar que el contacte directe moltes vegades és poc eficient, tot i que es realitzi amb la millor voluntat, perquè determinades indicacions donades pels professionals poden trobar resistències reals i dosis impor- 
tants d'incomprensió i desconfiança. Tendim a pensar que els problemes de comunicació són tan sols lingüístics, que poden resoldre's amb l'ajuda de traductors, però sovint el que necessitem són intèrprets culturals, que puguin ajudar a comprendre el punt de vista de l'altre i afavorir així el diàleg, la negociació i la presa de decisions. Aquest seria el sentit que es donaria a la mediació cultural, la tasca de facilitar l'accés i la comprensió de les funcions i el funcionament de les institucions educatives als professionals de l'educació, el perquè de determinades actituds, accions i decisions, a fi que no les jutgin ni les interpretin a partir dels seus propis paràmetres culturals (Llevot, 2002). Les tasques de la mediació, tant si són espontànies com si no, busquen caracteritzar-se per la seva tasca de descodificació i comprensió dels contextos culturals que s'interrelacionen. Malgrat això, en les actuals condicions de desigualtat objectiva, s'acostuma a utilitzar la reivindicació amb l'objectiu del reconèixer i acceptar les diferents cultures en contacte i com a projecte de convivència.

A Catalunya, davant la poca documentació teòrica i empírica sobre aquest tema, vam voler aprofundir les experiències fins ara realitzades d'aquesta nova figura que exigeix la construcció d'una pràctica i una teoria pedagògiques estrictament lligades a la realitat actual en l'àmbit de les relacions de persones de cultures diverses. Per aprofundir-hi, vàrem optar per una metodologia qualitativa: les entrevistes en profunditat. Tot i la idea prèvia d'establir una mostra, es va prendre la decisió d'entrevistar tots els mediadors interculturals que trobéssim que intervinguessin en centres educatius de Catalunya, ja que vàrem anar detectant que no es tractava d'un nombre excessiu. Així, després de molts esforços per localitzar els nostres interlocutors potencials (a través d'entitats no governamentals, ajuntaments, consells comarcals, associacions d'immigrants i gitanos, etc.) vam finalitzar el treball de camp amb vint-i-set entrevistes ${ }^{1}$ en profunditat a mediadors.

Fruit d'aquest treball empíric, podem dir que els dos col-lectius que s'han interessat (o que l'Administració ha potenciat que els interessi) per la mediació intercultural són els gitanos i els immigrants estrangers. Col-lectius considerats minories ètniques, és a dir, en situació d'inferioritat o de marginació en relació amb la majoria social, ja sigui per discriminació jurídica, inseguretat en l'estatus de resident, no accés a la ciutadania, falta de drets polítics i socials,

1. El treball de camp es va realitzar per tot Catalunya, va començar al juliol del 2000 i va acabar al setembre del mateix any. Abans, però, hi va haver uns passos previs: el mes de gener es va escriure una carta a directors de fundacions, associacions, etc. de tot Catalunya que tenien o que podien tenir mediadors i que realitzaven o que podien realitzar formació de mediadors interculturals, especialment en el camp educatiu, amb el propòsit d'explicar-los l'estudi i demanar-los la seva col-laboració. Com que van respondre pocs, al cap de tres mesos, a l'abril, es van fer trucades per concertar una entrevista personal amb ells. Els criteris mínims per triar-los eren: que estiguessin exercint com a tals, especialment en l'àmbit educatiu; que fossin de cultures diferents; d'edats heterogènies; dels dos gèneres; persones reconegudes com a tals per la societat d'origen i d'acollida amb una xarxa relacional extensa en totes dues parts; amb un temps d'estada a Catalunya superior als dos anys, i, per últim, que actuessin preferiblement en l'àmbit educatiu. 
impediments a la mobilitat social i econòmica, discriminació ètnica, etc. Els més afectats són els gitanos (ciutadans espanyols des del punt de vista jurídic) i els immigrants magribins i subsaharians. Per això, quan parlem de població immigrada estrangera, ens referim a un conjunt plural i heterogeni, en el qual malauradament l'origen nacional o cultural és important pel que implica; es tracta de persones immigrades d'origen estranger $i$, en concret, aquelles que no disposen de l'estatus legal de refugiat polític, sinó immigrants la motivació dels quals ha estat principalment econòmica — tot i que som conscients de la fragilitat de dividir entre migració política i econòmica, perquè sovint totes dues estan interrelacionades-, és a dir, els sol.licitants de refugi pateixen necessitats econòmiques i als països d'origen la situació política (per exemple, la d'un règim dictatorial) dificulta que la població trobi una sortida laboral. El que cal dir des de l'inici és que no apareixen, entre els mediadors, immigrants comunitaris, que, en nombre creixent, resideixen a les comarques catalanes, ja que aquesta nova comunitat està formada principalment per professionals lliberals i per jubilats i, pel que sembla, la seva millor situació social, econòmica, etc. fa "que no els en calgui». També s'ha d'esmentar que, en general, s'identificava gairebé sempre el terme immigrant amb les persones originàries de països no comunitaris. Cal concretar que en l'esmentat treball empíric, hem realitzat dues entrevistes a mediadors de l'anomenada "segona generació» (entenent com a tal la descendència de famílies d'origen estranger) — terme que ha estat qüestionat per diversos autors, perquè connota una línia de continuïtat cultural i de posició social entre pares i fills i pot contribuir a estigmatitzar des del naixement els qui van néixer d'uns pares que un dia van ser immigrants i alguns que ja han nascut a Catalunya. Com es fa en altres contexts, seria més adequat referir-nos-hi com «d'origen immigrant», tot i que també utilitzarem «segona generació» però entre cometes. D’altra banda, l'altre col-lectiu pel qual ens hem interessat és el gitano. El fet és que a Catalunya, i en concret pel que es refereix a les institucions educatives, alguns gitanos s'han dedicat a exercir tasques que podem situar dins l'òrbita de la mediació intercultural, fins i tot, en molts casos, se’ls dóna aquest nom afegint-hi el terme gitano («mediador gitano»), pel fet que actuen, específicament, amb el seu col.lectiu.

Per anar situant el lector, és imprescindible fer un perfil dels mediadors existents, per això detallarem algunes de les seves característiques, tant si intervenen a temps complet com a temps parcial en les institucions educatives de Catalunya. Així, tractarem primerament el perfil general, per analitzar, posteriorment, el perfil real i ideal que presenten aquests mediadors, entre altres qüestions.

\section{Qui són els mediadors interculturals que actuen a Catalunya?}

Per aproximar-nos als mediadors, és important definir qui són les persones que fan aquesta tasca —això no vol dir que siguin els més adequats, com veurem-. Així, ens referirem a l'edat, el gènere, la procedència, el lloc on treballen, el temps que fa que viuen a l'Estat espanyol en el cas dels d'origen immigrant, etc. 
En primer lloc, l'edat, que presenta una diferència notable entre immigrants i gitanos, augmenta considerablement en el segon grup, tot i que hi ha joves procedents dels dos col-lectius als quals els interessa la mediació com a futura inserció laboral. Quant al gènere, es troba bastant igualat, tot i que hi ha un insignificant predomini del gènere masculí. Per col-lectius, observem que, pel que fa al col.lectiu gitano, s'obre al gènere femení com un nou filó ocupacional que fins ara era reservat, únicament, al masculí. Més enllà d'aquests dos trets identificatius, és interessant mencionar que, en conjunt, majoritàriament es tracta d'immigrants, concretament només cinc són gitanos i vint-i-dos mediadors són d'origen immigrant. Entre aquests darrers, el continent més representat és l'africà i, dintre d'aquest, el contingent més important és el marroquí ${ }^{2}$. De més nombre a menys, els orígens d'aquests mediadors és: tretze marroquins; tres senegalesos; dos algerians; dos de gambians. Es tracta principalment d'africans, però també és cert que n'hi ha d'altres orígens: un del Brasil (Amèrica del Sud) i un de la Xina (Âsia). Una dada que cal recordar és la no-aparició de mediadors com ara equatoguineans, dominicans, etc., fet que dóna suport a la tesi que aquestes minories passen més desapercebudes perquè no tenen el problema de llengua, així com que no susciten estereotips tan negatius com ho fan, per exemple, els gitanos.

D'altra banda, per fer-nos una idea de la distribució geogràfica dels mediadors, aquests són més presents a les poblacions de les rodalies de Barcelona i de Girona - fet relacionat amb la presència de la població gitana o determinats orígens immigrants; com també és on sembla que hi ha més sensibilització en les institucions escolars-, tot i que també apareixen en altres indrets. Es pot dir que en força comarques encara no trobem la presència de mediadors, però un possible indicador que en el futur hi podrien ser és l'interès que hem comprovat que tenen els ajuntaments, els consells comarcals, les associacions d'immigrants i gitanos, etc. per la mediació i el desenvolupament de projectes en aquesta línia.

Respecte al coneixement de les dues llengües oficials de Catalunya, el català i el castellà, tots les entenen totes dues, però poc més de la quarta part parla el català (tot i que n'hi ha alguns que el barregen amb el castellà — per tenirhi més fluïdesa-), en canvi, tota la resta s'expressa en castellà i a algun se li escapa alguna paraula en àrab i en francès. En aquest punt, cal dir al seu favor que els d'origen immigrant coneixen altres idiomes, com ara el francès i/o l'anglès (d'acord amb la llengua oficial que tenien al seu país, la majoria dels quals van ser colònies de països europeus) $i$, per descomptat, dominen la llengua $o$ fins i tot llengües del país d'origen. També entenen (tot i que potser no les parlen) altres llengües dels grups ètnics més propers al seu col-lectiu. Per concretar més, els mediadors magribins dominen l'àrab i, en algun cas, sobretot si són propers a una zona rural, també el berber. Pel que fa als d'origen subsa-

2. Dada que es correspon al fet que és el col-lectiu estranger més important a Catalunya, amb un total de més de 60.000 residents (Moreras, 2001). A partir de les entrevistes, hem detectat que, concretament, la majoria vénen de Nador, Laraix i Kasar el Kebir. 
harià, coneixen, principalment, mandinga, fula, wòlof i sarakhulé. La mediadora brasilera coneix el portuguès i la mediadora xinesa, el mandarí. El coneixement d'aquestes llengües és considerat imprescindible per intervenir, tot $\mathrm{i}$ que destaquen que aquest criteri no és una garantia suficient, la qual cosa erosiona l'aposta que alguns poden fer pel traductor o l'intèrpret lingüístic sense formació en mediació. A més, justifiquen — extensament - aquesta idea perquè creuen que també s'ha de dominar el llenguatge no verbal, és a dir, l'expressió gestual que presenta significats heterogenis segons la cultura i que pressuposa una interpretació cultural i complementària de la informació. Això implica que els mediadors d'origen immigrant prefereixin intervenir amb els col-lectius més propers al seu, ja que l'operativitat i efectivitat serà més gran com més gran sigui la proximitat lingüística i cultural. Malgrat l'anterior, consideren que, en algun cas, es podria fer comediació amb persones autòctones. Pel que fa als mediadors gitanos respecte al coneixement del caló, tots el coneixen i abans l'utilitzaven regularment, però, darrerament, s'ha perdut molt. Com és lògic, aquest fet preocupa els mediadors de més edat, que lamenten la pèrdua de l'idioma, dels costums, etc. que va sofrint la seva comunitat.

Quan vam començar el nostre interès per la mediació, vam considerar bàsic saber si havien realitzat el pas anterior a la mediació "professional», és a dir, la natural (si havien mediat amb la seva família, els seus companys, etc.). Concretament, els mediadors gitanos van dir que ho havien fet «des de sempre», com una pràctica voluntària, per arreglar conflictes en la seva comunitat fins al moment que l'Administració els va proposar que ho fessin de forma reconeguda. No hem d'oblidar que la figura de l'home de respecte forma part de la cultura gitana. Pels gitanos, el seu poble és el pioner en el tema de la mediació, per això, ells sempre ho han vist com a pràctica espontània i no els ha costat entomar aquest paper (sorgeix «naturalment» de la seva comunitat).

També hi ha força exemples de mediadors immigrants que s'atribueixen l'origen de la mediació, recorden al seu país d'origen una persona que feia aquesta funció substituint el model jurídic colonial de tipus occidental, com si es tractés d'un jutge de pau. Allí, cada clan té un cap, que, generalment, és l'ancià més venerat en virtut de la seva experiència de vida i gaudeix del respecte general, perquè és el representant dels avantpassats. Aquesta figura no disposa d'elements coercitius per imposar la seva autoritat, però se l'obeeix perquè és el costum i la tradició els que ho dicten així i els conflictes que no solucionen s'envien als tribunals. D'altres fonamenten el camí recorregut fins esdevenir mediadors en l'ajuda quotidiana, no tant en la resolució de conflictes, sinó en la solidaritat interna, en les relacions i la cooperació entre les persones, per això han realitzat tasques semblants al país d'acollida.

Aquest paper de mediador natural, com veiem, el realitzaven i el realitzen de forma voluntària davant la marginació, l’aillament i la segregació que pateix el seu col-lectiu a la societat majoritària. La novetat és que ara la societat es faci càrrec de donar resposta a aquesta necessitat i que es faci des d'una creixent institucionalització i anant donant un paper rellevant a aquesta figura. Els mediadors gitanos coincideixen a dir que els polítics, per recuperar la seva cre- 
dibilitat, necessiten persones del carrer, que surtin i que visquin amb els propis col-lectius minoritaris.

En general, la pràctica de la mediació l'exercien, de forma natural a les comunitats de persones immigrades, els subjectes que, pel seu millor coneixement de la llengua i del país, ajudaven els seus compatriotes acabats d'arribar en el seu procés d'adaptació. Servien com a traductors en la tramitació de papers i sol-licituds d'ajudes, donaven suport i aconsellaven davant de problemes i dificultats. La pràctica de la mediació ens demostra que la seva capacitat per complir amb la funció social, que tant professionals de serveis com població immigrada necessiten de la mateixa manera, es veu truncada per les condicions en què es realitza i per la seva complexitat inherent. Per tant, anirem insistint en la necessitat que hi hagi una formació adequada ${ }^{3}$ dels mediadors que defineixi clarament el seu rol, les seves funcions i els seus límits i que els proporcioni una competència tècnica, condició fonamental per construir una col-laboració professional fructífera amb els agents socials i les persones minoritàries usuàries.

Un altre tret interessant és el temps durant el qual havien realitzat aquesta activitat com a pràctica espontània i voluntària abans que fos una feina per a ells. Els homes gitanos segueixen dient que ho han fet sempre, des que han estat considerats tios ${ }^{4}$ per la seva comunitat (se'n consideren cap als quaranta anys, aproximadament). Però els més joves no responen al mateix perfil, ja que ho han iniciat fa ben poc, tot i que ho han practicat informalment amb la seva família, el seu grup d'iguals, etc. En canvi, entre els mediadors (homes) immigrants el temps que fa que s'hi dediquen es correspon, en tots els casos, als anys que fa que viuen a l'Estat espanyol —ara bé, deixant sempre un temps prudencial de residència en la societat d'acollida (que varia en cada cas) ${ }^{5}$ fins que ells també se situen i coneixen les xarxes de la societat catalana, gràcies a uns altres agents espontanis - Entre les dones, en canvi, que, en general, fa menys temps que hi són, no es correspon el temps d'estada en la societat d'acollida amb el de fer de mediadores naturals.

Alguns mediadors immigrants han tingut un accés més ràpid a la mediació natural $i$, en canvi, a uns altres els ha costat més ser reconeguts pels seus companys (reconeixement necessari per desenvolupar aquest paper, ja que el pas a la "professionalització» els el donaria l'aval de l'Administració, les institucions,

3. En aquest sentit, es pot veure la proposta de formació desenvolupada conjuntament per AEP Desenvolupament Comunitari i Andalucía Acoge (2002).

4. «Si són avis de barons i si no hi ha cap defecte personal que ho impedeixi, llavors són tíos o tías amb independència que el terme pugui denotar també aquesta relació de parentiu. Se'ls pot dir vells si es parla d'ells: ho he de consultar amb els vells..., però hi ha vells que no són ni tíos ni tías. La gent gran que no ha tingut fills o que els ha perdut, els dements, els que tenen senilitat, no són tíos, són vells a seques» (San Román, 1994: 66).

5. Quant al temps que fa que viuen a l'Estat espanyol, almenys és de cinc anys, temps considerat suficient per «qualificar-los», per ajudar a integrar altres membres del propi col-lectiu. Com sembla lògic, el coneixement de la societat de recepció serà quelcom que caldrà tenir ben present en analitzar per què són mediadors (Garreta i Llevot, 2003). 
etc.). Resulta evident que es van adquirint destreses a mesura que van coneixent els mecanismes i els recursos de la societat d'acollida i es pot treballar, amb més eficàcia, per ajudar el seu entorn, per això a les dones — sovint relegades a l'esfera privada - els ha costat més conèixer la societat d'acollida i assumir aquest rol. Moltes vegades, el marit o el fill els acompanya als serveis, cosa que tergiversa el seu comportament quan es tracta, sobretot, de necessitats lligades a la salut o bé a la problemàtica familiar. Creiem que és important assenyalar-ho, perquè la dona és la demandant principal de molts serveis (atenció primària, educació, planificació familiar, etc.), però com que elles ocupen un segon lloc, sovint les pròpies parelles obstaculitzen el camí perquè esdevinguin mediadores. En canvi, trobem en les dones la millor disposició per participar en activitats interculturals a les institucions educatives i a les localitats on viuen.

En relació amb els àmbits en què s'utilitza la mediació i en què existeix més demanda per als dos col-lectius entrevistats, la realitat presenta un ventall de situacions, però és en el context dels serveis socials on aquesta és més gran. Això sí, li segueix l'àmbit educatiu, concretat, bàsicament, en les institucions escolars de primària i de secundària; l'àmbit sanitari (sobretot és important per als immigrants) i, després, l'habitatge. Entre els àmbits que són transversals, als primers trobem: les qüestions legals (pel que fa als papers dels immigrants), l'associacionisme i el treball, així com també les necessitats educatives, més minoritàries, que emergeixen en el camp del lleure.

Per sintetitzar, els mediadors en exercici de Catalunya tenen en comú que de fer-ho de forma natural van ser animats des de les associacions de base $\mathrm{i}$ entitats no governamentals, igual que n'hi va haver molts que van rebre el suport de l'Administració perquè esdevinguessin "professionals». La raó rau en el fet que aquesta volia que algú ocupés l'esglaó entre els professionals de la societat d'acollida o paia i els immigrants o gitanos. Però aquesta figura ha anat prenent la seva pròpia trajectòria i s'ha convertit, gairebé, en imprescindible per als professionals (com veurem més endavant), en comptes de preparar-los millor per acceptar nous reptes.

La diferència entre les diverses actuacions que poden fer - i que se'ls demana que facin- és considerar o no en igualtat de condicions els usuaris de les institucions o dels serveis autòctons. Des de l'òptica dels mediadors, els gitanos i els immigrants (evidentment, aquells del seu mateix origen) pateixen exclusió social: desigualtat i marginalitat respecte als autòctons, han de superar importants barreres lingüístiques i/o culturals, etc. Per tant, segons alguns es parla d'una mediació no neutra, en el sentit que s'orienta més a facilitar la igualtat d'accés i de tracte en els serveis que no pas en el fet que aquests també puguin adaptar-se a la nova realitat multicultural de Catalunya. Des d'aquesta òptica, la interpretació lingüística i cultural només és una part, tot i que molt important, de la mediació intercultural, i cal anar bastant més enllà en la prevenció i gestió de conflictes, així com en la transformació i catàlisi de les relacions entre col-lectius culturalment heterogenis.

Però de l'anterior es desprenen dos efectes perversos: per una banda, que les desavinences sobre la funció del mediador entre els diferents actors portadors 
d'expectatives diferenciades condueix a un mediador "penell», al qual se li demana que sigui una persona per a tot a l'escola, capaç d'executar qualsevol ordre en qualsevol moment; i, per altra banda, el segon efecte pervers és que el mediador s'arrisca a convertir-se en un agent de control a sou de la direcció o en un portaveu de la lògica de funcionament de la institució escolar i dels professors o, per contra, un emissari de les característiques de la situació de l'alumne.

Si concretem en els contexts d'intervenció dels mediadors gitanos, veiem que actuen, bàsicament, per a les administracions en les institucions educatives. El seu paper té a veure més amb les baralles, els conflictes, etc., és a dir, un àrbitre o jutge que arregla la situació perquè no arribi a més i s'aturi. Llavors, en entrevistar-los fan coincidir la seva resposta amb la necessitat d'aturar les situacions de malestar, de tensió... que comporten els problemes, perquè no vagin a més. En canvi, la visió del col.lectiu immigrant continua sent de caràcter polivalent inclosos els serveis socials d'atenció primària, a part de l'àmbit educatiu, la justícia, l'Administració, la salut, camps propicis per als mediadors interculturals, però no entesos solament com a traductors, sinó com a agents amb doble paper que interrelacionen totes dues collectivitats.

Els seus àmbits de treball desborden la idea de resoldre conflictes, malgrat que entenguem el conflicte de forma tan àmplia que englobi les situacions socials i interpersonals de manca de comunicació, malentesos, desajustament institucional, etc. Recordant els quatre tipus de mediacions que proposa Six (1997), les que anomena «preventives» $\mathrm{i}$ «curatives» estan destinades a detenir un conflicte, però també hi ha les «creatives» $\mathrm{i}$ «renovadores», que tenen com a finalitat fer néixer o renéixer una relació. La mediació intercultural és una modalitat de la mediació social caracteritzada perquè s'exerceix en un context de desigualtat social. En el cas dels gitanos, el context té a veure amb una gestió del conflicte que comporta connotacions negatives i repressives, és a dir, segons Six serien les primeres mediacions, les preventives i curatives; en canvi, als immigrants els correspondrien, més aviat, les segones, les curatives i renovadores; el conflicte esdevé una visió positiva, amb la idea d'enriquir-se mútuament i que les dues parts en surtin beneficiades, entenent-ho com un motor de canvi, per créixer dialècticament i caminar constructivament cap a un futur comú. Per tant, la forma de plantejar els problemes i gestionar-los serà molt diferent, els gitanos actuaran amb la intenció de tallar-los o evitar-los, en canvi, els immigrants voldran afrontar-los directament i fins i tot provocar-los perquè surtin a la llum si encara estan en situació latent.

\section{El perfil real i el perfil ideal}

Una vegada hem conegut el procés pel qual s'ha esdevingut mediador, a continuació ens proposem concretar més el perfil i les competències bàsiques que tenen i les que haurien de tenir els mediadors segons ells mateixos i que, com veurem, no sempre coincideixen.

Com hem tractat en el punt anterior, tots els entrevistats havien fet abans mediació voluntària sense adonar-se'n, ja que era quelcom natural. Aquest pas 
previ és valorat com quelcom que s'ha d'haver fet: l'experiència de la mediació informal es considera imprescindible. A més a més, cal tenir o potenciar unes habilitats i unes característiques personals que possibilitin fer aquesta feina i adequar-s'hi. Aposten, doncs, per potenciar les habilitats socials per ajudar a comunicar-se d'una manera socialment efectiva. Tot i així, els gitanos tendeixen a considerar que les característiques són innates, perquè no tothom pot ser mediador. Concretament, els atributs són: ser una persona seriosa, saber escoltar l'altre, ser tolerant i gaudir del respecte i la confiança dels altres, qualitats que s'han de preservar i mantenir, en el cas del seu col-lectiu, al llarg de la trajectòria personal, a fi d'esdevenir una persona reconeguda i amb una conducta irreprotxable, igual que creuen que és una feina molt vocacional. Pel que fa als immigrants, la majoria destaca la confidencialitat i discreció, trets que els reconeixia el col.lectiu pel fet que ja eren abans mediadors naturals, pilars que tots consideren essencials perquè ara no els vegin com a confidents i ajudants de l'Administració. Entre els adjectius que escullen per definir les característiques personals que haurien de tenir destaquen: empàtic, assertiu, flexible, madur, equilibrat, pacient i optimista; tots aquests trets es consideren essencials per a aquesta feina. Però, a més, consideren que no sols són necessàries per a aquesta figura, sinó que també les troben útils per a unes altres professions del camp social. Hi afegeixen que moltes d'aquestes habilitats socials es treballen en els cursos de formació per a mediadors, tot i que per a la majoria són de caràcter innat.

Els que fa més temps que treballen com a mediadors "professionals» creuen que també s'ha d'evitar que determinades situacions i tensions entre les parts (no sempre disposades a negociar, sobretot, per part del col-lectiu autòcton) els involucrin i els afectin massa en l'aspecte personal. Això diuen que els ha passat a alguns mediadors, que han arribat a somatitzar els problemes aliens $\mathrm{i}$ a patir estrès i depressions (com també li ha passat a algun mediador gitano), per això consideren important que sigui una persona equilibrada psicològicament, amb un alt grau d'autocontrol, per mantenir la calma i tenir la paciència necessària que condueixi a la solució dels problemes i de les complexes experiències, sobretot en benefici de la pròpia salut mental. Alguns, però, per solucionar aquest darrer punt, apunten la necessitat de treballar en un equip multiprofessional, des de la complementarietat i mai des de la substitució de funcions en els casos en què intervenen. Algunes experiències ens diuen que cal cercar una mediació compartida per un equip de persones pertanyents a cada àmbit, així s'hi poden aportar sensibilitat i valors diversos. Cal buscar la complementarietat i l'efecte psicològic que es transmet quan l'equip mediador està format per persones de les diferents parts. Sobre la importància de treballar en equip, es creu necessari delimitar molt bé les funcions de cada un dels professionals que treballen amb el mediador per configurar un projecte comú, d'aquesta manera s'evitaran malentesos i desconfiances dels uns envers els altres.

La formació també és important en la definició del rol i el reconeixement del mediador. Si aquest està ben format, la relació amb l'equip té més possibilitats d'establir-se d'igual a igual. El repte, pels entrevistats, no és solament defi- 
nir les àrees i les funcions que han de desenvolupar els mediadors, sinó elaborar estratègies conjuntes d'acció que ho facilitin. S'apunten, entre altres, possibles col-laboracions en l'àmbit educatiu: en els programes i serveis educatius ordinaris d'atenció a les minories ètniques i culturals, en els mateixos equips i departaments d'orientació escolar dels centres educatius i en equips interdisciplinaris externs, etc. La formació que tenen els que realitzen la funció de mediadors interculturals a Catalunya presenta un gran contrast entre el col.lectiu gitano i l'immigrant, que, paral.lelament, s'extrapolarà al seu ideal de mediador. Per una part, el perfil real dels gitanos de més edat és que tan sols tenen estudis primaris (mínim coneixement de la lectoescriptura i el càlcul) i alguns potser, fins i tot, sense acabar, però de fet tampoc no els han necessitat per trobar feina com a mediadors, per tant, no consideren que els estudis siguin quelcom prioritari. La majoria dels mediadors immigrants tenen estudis superiors - almenys iniciats - realitzats al país d'origen, tot i que no se'ls hagin convalidat en arribar a l'Estat espanyol. Concretament, alguns marroquins tenen estudis, principalment de carreres de lletres, alguns sense acabar ${ }^{6}$, d'altres finalitzats però els han intentat convalidar sense èxit al país d'acollida i no els han servit per trobar feina, per la qual cosa treballen en altres oficis de menys preparació acadèmica i baixa consideració social. Per tot l'anterior, els immigrants s'inclinen més per valorar en el perfil ideal del mediador que tingui estudis, si pot ser, com la majoria indica, de tipus universitari. Fins i tot, en algun cas, es critica que hi hagi diferències entre els mediadors que tenen estudis i els que no, que són observades tant pels professionals com pel resultat del procés de mediació. Evidentment, els que tenen formació, encara que no estigui acaba$\mathrm{da}$, la valoren més que uns altres que no en tenen.

En síntesi, no es tracta de crear xarxes paral.leles, ni tampoc elements de distorsió de la convivència dins la societat, sinó que les persones que requereixen atenció especial puguin gaudir de la mateixa qualitat de serveis dins la xarxa normalitzada. A més de formació, també creuen que cal suport, els mediadors insisteixen que és necessari fer quelcom per no esgotar les seves capacitats, és a dir, arribar al seu límit. Una forma de treballar aquesta qüestió és oferir ajuda professional, d'aquesta manera es podrien prevenir les situacions d'estrès que comporta aquesta feina, per exemple, a través de la supervisió — consistent en sessions periòdiques d'acompanyament psicopedagògic a càrrec de persones especialitzades_-, l'aclariment del paper i la funció de la mediació - precisar els seus límits, trobar solucions per a casos complexos, etc.mitjançant la potenciació de la coordinació i l'establiment de reunions amb altres mediadors i professionals. En aquest sentit, una iniciativa que serveix per elevar l'autoestima i la salut mental consisteix a potenciar la seva promoció interna dins el mateix servei.

6. Tal com ens han dit, en el transcurs de les entrevistes, pensaven acabar la carrera en arribar al país d'acollida, però no els ha estat possible per diversos motius (en haver de treballar moltes hores i en feines molt pesades, motius econòmics, llunyania de la universitat, entre d'altres). 
Els mediadors d'origen immigrant afegeixen a tot l'anterior el fet d'haver viscut en carn pròpia el trauma migratori, és a dir, sentir la migració com un procés de dol que comporta pèrdues en l'aspecte psicològic i psicosocial, ja que es deixen els familiars, els amics, la llar, l'estatus, etc. al país d'origen, amb la consegüent alteració de l'autoestima, els valors, els costums, les tradicions, etc. al país d'acollida, i no veure gairebé mai satisfet el projecte migratori, entre d'altres. Evidentment, és un tret específic dels immigrants i que cap gitano ha destacat — tot i ser possible, ja que també podien haver-se referit a migracions viscudes i a la itinerància que es pot donar dins l'Estat espanyol-. Ajudar els altres a superar el trauma que crea la migració no ho consideren una tasca facil, ja que s'ha de ser capaç de transmetre serenitat, optimisme i confiança en el futur al col-lectiu, tant si tenen el desig de restar a Catalunya com de retornar al país d'origen. Consideren que per superar el trauma migratori, endinsar-se en la nova societat i dominar els serveis d'aquesta han de passar, com a mínim, cinc anys. Recordem que n'hi ha molts que van arribar a ser mediadors "professionals» després de transcórrer uns anys en el nou destí.

Els mediadors gitanos, els magribins i els subsaharians (d'entre ells, preferentment, els que treballen en poblacions petites) comparteixen que el reconeixement del seu col-lectiu està relacionat $\mathrm{amb}$ el fet de viure d'acord amb els principis de la religió musulmana, sobretot guardant les aparences, conservant les tradicions, etc., de cara al col-lectiu perquè els tinguin confiança i credibilitat perquè són com un d'ells. En canvi, els que treballen en localitats grans consideren que això no és tan important, sinó que s'ha de ser un bon professional de la mediació.

Quant a l'edat real i la ideal per fer de mediador, el fet que els gitanos majoritàriament siguin grans (els entrevistats tenen més de cinquanta anys) creuen que presenta beneficis, perquè l'edat representa experiència i prestigi, i això recorda la importància dels tíos i els patriarques, en correspondència als criteris de jerarquia interètnica, tot i que tindria el perill d'identificar el mediador amb la figura de l'àrbitre o del jutge, com sovint succeeix. La resta coincideix en l'edat mínima aproximada, que hauria de ser els trenta anys o més; cap amunt no es fixa cap límit màxim, principalment perquè l'increment d'edat es relaciona amb la maduresa i la saviesa de la persona. Cal recordar que la mediadora gitana, més jove, treu importància a l'edat, però els trenta anys, dins els quals ja s'inclou, és l'edat que creu mínima.

Respecte a si és millor o indiferent el gènere del mediador, quasi la totalitat creu que no s'han de fer distincions. Així, n'hi ha alguns que, per la seva experiència, veuen millor la formació d'equips mixtos que atenguin les múltiples necessitats que es puguin presentar en els diferents àmbits. Però existeix, gairebé, un consens entre els mediadors, en el sentit que a l'hora d'actuar el mediador ho faci amb el seu gènere de referència. Així, els homes gitanos reconeixen que els ha costat bastant — sols ho han pogut fer gràcies al reconeixement d'honestedat i decència que ja tenen- entrar a mediar o quedar-se sols amb les dones, sobretot que els obrin la porta si no hi ha el marit i si estan soles a la seva llar. 
Pel que fa als immigrants, la situació és diferent, la mitjana d'edat que tenen els mediadors és bastant més jove, se situa en més de trenta anys (que correspon a l'edat mínima establerta — vint-i-cinc anys - per fer alguns cursos de mediació), tot i que prioritzen la maduresa i l'experiència personal a tenir una edat determinada. Els que tenen més preparació i formació en aquest camp creuen que ha de prevaler conjuntament amb la maduresa, més que una edat o un gènere específic. En general, l'edat, pels mediadors immigrants, no és sinònim ni garantia de res, perquè en cada cultura té un valor $i$ un pes molt relatiu. Però també és cert que els mediadors immigrants més grans presenten la seva edat com un valor, ja que comporta més maduresa i preparació, i creuen que la seva eficàcia com a mediadors rau en aquestes característiques, difícils d'obtenir en una persona molt jove. Tot i que, sovint, al país d'origen dels immigrants la comunitat està ordenada en funció d'una jerarquia i cada persona desenvolupa un rol en virtut de diferents factors, un dels quals és el grup d'edat al qual es pertany, a Catalunya, la situació és diferent, per això els mediadors adults prefereixen les qualitats personals, que fan que s'ocupi una posició de prestigi o una altra en el si de la comunitat.

Quant al paper del gènere, aquest pren més rellevància que en el cas dels gitanos, especialment quan es refereix al femení, ja que predominen més experiències negatives de gèneres creuats, tant d'homes mediadors que han mediat amb dones com, a l'inrevés, de dones mediadores que han mediat amb homes. Sobretot aquest fet depèn de la procedència dels destinataris de la intervenció, definida en forma de binomis oposats: ciutat-camp, àrab-imazighen. Un exemple és el viscut per alguns nouvinguts de zones rurals respecte a l'àmbit sanitari $i$ a les visites ginecològiques. Cal destacar que, en aquesta direcció, s'ha fet formació sanitària als immigrants, amb l'objectiu que adoptin els hàbits higiènics i alimentaris considerats, des del punt de vista mèdic, òptims, a fi d'establir protocols clínics per detectar algunes malalties (de transmissió sexual, d'origen tropical, etc.). En aquesta línia, també s'han adoptat recursos i traductors, sovint relacionats amb les mateixes comunitats d'origen, o bé s'han organitzat tallers d'educació sanitària adreçats, únicament, a dones africanes per evitar la interferència de tabús sexuals. Per tot l'anterior, algunes dones immigrants utilitzen amigues, veïnes, etc. que fa més temps que són a la ciutat perquè els facin d'acompanyants i traductores; recorren a la mediació natural abans que a la mediació "professional» (sobretot si es tracta d'un home). Igual com feia el col-lectiu gitano, els homes immigrants també desconfien d'entrar a casa, de quedar-se a soles amb la dona sense que hi hagi ningú més present a la llar. Només en casos de molta confiança seria possible; en la resta de situacions, la majoria, això no es veu convenient. Malgrat això, els més formats en mediació intercultural emfasitzen que la competència professional pot traspassar la qüestió del gènere.

En general, els mediadors interculturals es mostren favorables a l'exercici d'aquesta funció per part de les dones, sobretot en alguns àmbits (com pot ser el de salut). Aquesta característica creuen que comporta una absència de judici i una llibertat d'expressió lligades a una comprensió més bona entre iguals. 
Però no oblidem que n'hi ha alguns que no estan gaire satisfets amb això. Si detallem més aquest punt, veurem que s'observen dos àmbits en què es creu que l'home és més eficient: l'habitatge i el laboral; en canvi, per a la resta es considera que la intervenció de les dones és igual o millor. Entre els avantatges que s'apunten a la incorporació de dones destacarem: més motivació per a la formació, més experiència en el tema familiar, el desig d'integrar-se en la societat $\mathrm{i}$, finalment, convertir-se en exemple de motivació i referent positiu per a la integració dels fills.

Quan els mediadors han fet referència a la necessitat de conèixer la cultura "majoritària», tots consideren que és molt important per assolir la integració i és imprescindible per poder-se moure, demanar ajudes i accedir als serveis de la societat, sense que això pressuposi una adaptació a la forma de viure del món paio (per als gitanos) o occidental (per als immigrants), però sí que comporti menys conflictes i tensions. Pel que fa als gitanos, tots els mediadors saben que la integració en la societat paia és necessària i positiva per al seu col-lectiu, però també observen amb preocupació aquesta integració pel que comporta d'anul.lació de la seva cultura i identitat. Es proposen reforçar i preservar la identitat cultural pròpia alhora que es vinculen a la societat majoritària per obtenir-ne beneficis.

Els mediadors gitanos desitgen integrar-se a la societat paia, però es mantenen hermètics i inamovibles en alguns punts clau de la seva cultura, sobretot pel que fa a la permissivitat amb les dones i la conservació de les noies verges fins al matrimoni. Això fa que entenguin les postures dels progenitors, que, quan les prometen, sovint les retiren de l'escola per evitar que caiguin en perills. Una afirmació totalment contradictòria amb el que pensen mediadores més joves, que consideren anquilosat el paper atorgat a la dona en la seva cultura i reivindiquen una postura més oberta per a la gitana actual.

En canvi, els mediadors immigrants no semblen tan «resistents» culturalment i identitàriament, ja que es decanten per integrar-se a la societat d'acollida en aspectes de conèixer i introduir-se en la cultura del país (entorn social, cultural, etc.). La seva aposta és mantenir la seva cultura en la seva comunitat, és a dir, en l'esfera privada (per exemple, en les festes), però cal dominar la pública de la societat majoritària, tot i que tampoc els agrada que els diguin que s'han tornat occidentals o europeus. Sobretot consideren que cal conèixer els aspectes del funcionament de les lleis i les administracions del país d'acollida per poder ajudar a donar a conèixer al seu col-lectiu l'accés al treball (situació jurídica per obtenir el visat i ser regular), l'habitatge, la sanitat i la seguretat social, l'educació, etc. en la societat receptora, sense perdre de vista els aspectes més conflictius que poden comportar friccions amb els del país d'origen. També apareix, en algun cas, una confrontació directa de la seva cultura amb l'occidental, que es considera perniciosa respecte als valors propis ${ }^{7}$. Hi ha un

7. Tal com expressa aquest mediador senegalès: «iOh! es europeo, ha cambiado la mentalidad, ahora es africano pero dentro es blanco... la gente dice se ve negro pero dentro es blanco, 
temor per la pèrdua d'identitat quan fa molt de temps que s'està al país d'acollida, i això creuen que pot ser contraproduent, perquè quan fa massa temps que s'està immers en una altra societat, un s'oblida de la cultura d'origen i s'acomoda a la de destinació. Integrar-se a la societat catalana no hauria de ser simplement un procés de pèrdua d'identitat i de valors per tal d'imaginar-se homogeni i normalitzat respecte a la resta. N'hi ha alguns que, encara que parlin la llengua de la societat d'acolliment, continuaran tenint uns trets físics particulars dels quals no podran desfer-se facilment.

Una qüestió que cal remarcar, que consideren força important, té a veure amb el coneixement de la llengua catalana. Els mediadors gitanos, en general, creuen que hauria de ser bàsic per als mediadors que treballen a Catalunya. Pel que fa als immigrants, consideren molt important conèixer i integrar-se en la societat d'acollida i en la seva cultura, però, respecte a la seva actitud quant al coneixement de les llengüies oficials (català i castellà), tot i que reconeixen que és essencial per a la seva integració i que a molts els agradaria aprendre el català, n'hi ha pocs que dominin la seva expressió oral i escrita. Mitjanament dominen el castellà; en aquest sentit, en alguns cursos de mediadors (tot i que es fan a Catalunya) es realitzen diverses sessions en llengua castellana (cosa que també es produeix amb els que van dirigits al col-lectiu gitano). De fet, n'hi ha alguns que han començat a fer cursos de llengua catalana a les associacions, dintre de les opcions lingüístiques que ja portaven a terme (bàsicament cobertes per voluntariat) —els mediadors més joves, gitanos i immigrants, consideren aquest punt un pilar bàsic en la seva integració-. En realitat, s'ha incrementat la demanda sobretot de cara a una futura inserció laboral, tant d'ells com dels seus fills, així com perquè han vist que afavoreix la relació amb la societat receptora. A més, més enllà de l'aprenentatge lingüístic, en els cursos que realitzen es vol anar cap al coneixement de l'entorn social -en el sentit que puguin aprofundir la cultura pròpia de Catalunya.

Sobre l'origen ètnic o cultural del mediador, tots els entrevistats són del mateix parer, prefereixen que el mediador pertanyi al mateix grup cultural que el col-lectiu minoritari, perquè coneix millor el grup des de dins. L'elecció preferentment de persones minoritàries per les institucions obeeix a una opció de discriminació positiva dels col-lectius més desfavorits, amb la doble funció de sensibilitzar els professionals i, a la vegada, garantir la igualtat d'accés i utilització dels serveis per part dels usuaris minoritaris. Però també és possible identificar alguns perills per ser membre d'una minoria: fer de portaveu, considerar-se'n un referent, entre altres; però el més acusat el tindran en l'aspecte identitari.

L’idioma és una part de la cultura d'origen que és indispensable de dominar per poder-hi actuar. Per tant, si algú no el coneix prou, ja no és adequat per a aquella situació. Però tampoc no creuen que la seva actuació s'hagi de

ha cogido las costumbres de Europa [...] no es como nosotros, es negro de fuera y blanco de dentro". 
reduir a traduir, funció que es du a terme en molts casos, segons alguns mediadors entrevistats, sinó que es tracta de dominar els dos codis culturals en joc ${ }^{8}$.

Els mediadors creuen que també se'ns escapen uns altres aspectes de la comunicació. Sovint, només recordem els fenòmens que percebem a través dels sentits (l'oïda, la vista, l'olfacte, el gust i el tacte), és a dir, la paraula, la imatge, la gesticulació, la mímica i altres fenòmens corporals com ara els missatges subliminars. Sembla, però, que hi ha d'altres formes de comunicació a més de la verbal i la corporal. El nucli d'aquest repte és la nostra capacitat i competència per comunicar-nos de manera intercultural.

En síntesi, tot i les excepcions, els mediadors gitanos, magribins i subsaharians — i, dins d'aquests darrers, marroquins, algerians...- - prefereixen mediar amb el propi col-lectiu de pertinença, ja sigui per factors culturals (pautes, normes, llengua, religió, cosmovisió, etc.) com per la confiança que desvetllen en els seus «iguals». Matisant tot l'anterior sobre la conveniència de procedir del col-lectiu minoritari a l'hora de mediar, hi afegeixen la importància que a l'hora de procedir s'ha de ser imparcial, i ajudar que les parts negociïn sense imposar res a ningú. Així doncs, centren les seves actuacions en un compromís d'un procés en què el resultat satisfaci totes dues parts, construint una distància entre ells i la problemàtica de les parts i derivant a d'altres associacions i/o entitats quan el procediment no sigui correcte, és a dir, una de les dues parts no vulgui dialogar o negociar.

Després de referir-nos al coneixement de la cultura de la minoria i de la cultura de la societat majoritària, cal aprofundir una qüestió clau per a nosaltres: el coneixement del sistema educatiu. Respecte a aquest coneixement i, concretament, de l'escola com a institució socialitzadora, s'obtenen, segons els mediadors i el col-lectiu, dues posicions diferents i contraposades: per una banda, la importància que atorguen els mediadors (pagats per l'Administració) al sistema educatiu (i, en concret, a les institucions escolars) per ajudar les properes generacions i, per l'altra, la visió del propi col-lectiu minoritari.

Els mediadors destaquen la importància de conèixer a fons el sistema educatiu i el funcionament de les institucions escolars per tal de mediar, i alguns de convèncer de la seva importància, en el grup ètnic o el col-lectiu d'origen. En tots els casos, és imprescindible que tinguin coneixement de les pautes i dels codis culturals de les dues parts en litigi. Si les confrontacions es produeixen com a efecte del procés d'escolarització, també és indispensable que estiguin ben informats de les pràctiques i, en el cas dels immigrants, de la valoració i el sistema de l'escolarització en els països d'origen i també, evidentment,

8. «Perquè moltes vegades els mediadors no fan més que d'intèrprets o traductors lingüístics, però no fan de traductors culturals [...] la mediació aquí a Catalunya encara no és mediació real, el que fem és, la majoria que hi som, és traducció o com a màxim interpretació, però és una interpretació lingüística $[\ldots]$ jo no dic que no, però han de conèixer com a mínim l’idioma d'origen... dominar les llengües... Si parles dos idiomes bé i entens bastant com a mínim de les dues cultures, i la religió, els valors humans que hi ha aquí, els valors que hi ha allà, la jerarquia familiar que hi ha, els rols...». 
del sistema en ús en el país receptor. Pel que fa als mediadors gitanos, l'experiència professional (a les associacions, etc.) que han tingut en intervencions escolars anteriors és determinant per a la feina que actualment realitzen, ja que coneixen els centres, els professors, l'horari, etc.

Sobre el que hauria de conèixer un mediador, respecte a l'àmbit educatiu per fer la seva tasca, consideren imprescindible conèixer un mínim del funcionament de les escoles — que es va aprenent, a poc a poc, sobre la marxa—. Però, evidentment, creiem que cal més formació que la quotidiana. Els mediadors, per la seva part, destaquen com a més important el coneixement dels avantatges que pot tenir el sistema escolar per a les famílies gitanes. Per això, l'únic problema que tenen és saber convèncer els pares i els alumnes de la utilitat dels estudis, ja que fins aleshores els oficis tradicionals dels gitanos requerien un aprenentatge que proporcionava la participació en el món dels adults, no en la institució escolar, però actualment la situació ha canviat i es necessiten els títols per a gairebé tot. Aquesta situació és semblant a la del col-lectiu immigrant, en el sentit que els infants conviuen amb els adults, pares i familiars, no segregats. Això és així perquè es valora de manera molt positiva la convivència de diverses generacions juntes, els nens participen en els negocis, en les festes, en les activitats quotidianes, etc. Pares i fills comparteixen el mateix món. També cal dir que n'hi ha molts que recorden la seva experiència personal a les escoles del seu país i que comparen els procediments i els continguts amb els de la societat d'acollida, manifestant-ne la diferència i la necessitat que existeixin els mediadors. Segons els països d'origen, els sistemes educatius tenen més o menys semblances amb Catalunya. Evidentment, la semblança genera una comparació i una explicació més facil dels mediadors, tot i que les matèries i la implicació dels pares varia considerablement, igual que les expectatives dels pares sobre la institució escolar. Per això, el mediador ha de conèixer i explicar les similituds i les diferències entre els sistemes pedagògics.

\section{Reflexions finals}

La interculturalitat té un aspecte aplicat al desenvolupament de la mediació cultural: el contacte entre persones de cultures diferents pot ocasionar conflictes, incomprensions..., per raó del desconeixement mutu, l'absència de respecte $\mathrm{i}$ altres actituds relacionades amb la intolerància. La mediació intercultural, entesa com un element important de la integració, intervé en diversos nivells: presa de consciència per part de les minories ètniques dels valors i dels costums del país d'acollida, prevenció o solució dels conflictes provocats per les diferències culturals, així com també ha de tendir a modificar les actituds dels agents de la societat majoritària, que, constantment, es veuen obligats a qüestionar i reformular la seva pràctica.

De tot l'estudi anterior, sembla evident, per la seva mateixa existència, que a Catalunya calen persones que facin traducció i mediació en l'àmbit educatiu. La persona que realitzi aquesta feina haurà de conèixer el rol, les funcions i els límits del mediador polivalent — ja que sovint no treballen únicament en 
l'àmbit educatiu—, igual que les estratègies i les tècniques adequades per contribuir a gestionar dificultats i problemes que puguin donar-se en la relació entre persones culturalment diferents. En definitiva, a l'hora de treballar, caldria que tinguessin: experiència en contextos multiculturals; dots personals per a la mediació (diplomàcia, saber escoltar, etc.); coneixement de la llengua i de la cultura d'origen; coneixement de la societat d'acollida i de la seva llengua o llengües oficials, i coneixement de les xarxes socials i del funcionament de les institucions i dels serveis. Aquestes característiques ideals expliquen, si tenim en compte que s'ha d'actuar en àmbits on hi ha desigualtat objectiva, que els mediadors interculturals han de ser preferiblement del col-lectiu minoritari, car el seu perfil s'adaptarà més faccilment a les habilitats requerides.

Hem vist que no s'apunta un gènere determinat per mediar, però sí que surt la idoneïtat superior d'uns i altres en funció dels àmbits on es desenvolupi la mediació, sobretot tenint en compte que les dones estan relegades als espais privats i que els costa molt d'obrir-se a un home. En el cas de la dona, s'ha parlat, especialment, de l'àmbit de salut, per les seves connotacions especials, sobretot en el camp de la planificació familiar i dels maltractaments, tot i que sempre es pot matisar, segons l'especificitat del servei, les característiques personals dels usuaris, el lloc de procedència, els estils de vida, etc.

Arriba un moment en què la quantitat d'intervencions i les dificultats que comporta la utilització d'un servei no reconegut com ara la tasca de mediació (sobretot de traducció i d'acompanyament) espontània entre els col-lectius minoritaris i les administracions, que implica que no sempre estiguin disponibles, que la seva presència sigui intermitent, etc., obliga a fer un plantejament diferent, la "semiprofessionalització», que, això no obstant, manté la precarietat de les condicions laborals que pateixen les minories ètniques marginals a la societat d'acollida. Per això, la majoria (per no dir tots) dels mediadors estan en una situació molt inestable quant a contractació, jornada laboral i salari, independentment de si s'han tret el diploma de mediador o no, tot i que per a alguns és un fet consubstancial a les característiques d'una nova professió. En l'àmbit institucional, s'observa una gran desorganització i una manca d'unitat entre els practicants d'aquest ofici, de manera que, en general, els resulta difícil de poder sobreviure només amb això.

La figura del mediador encara és molt recent al nostre país, però en uns altres presenta una llarga trajectòria (Six, 1997; Garreta i Llevot, 1999; Llevot, 2000; Garreta i Llevot, 2003), es troba en un moment que intenta assolir la seva professionalització, direcció que alguns potencien. Per això, per tal d'unificar esforços i de compartir experiències, hi ha qui creu que s'hauria de tendir a la creació d'una cooperativa de mediadors, anant més enllà d'un nou jaciment laboral. Per als gitanos, aquest esdevenidor, ara per ara, sembla molt llunyà. En canvi, per als immigrants ja és un fet, perquè a Catalunya, com en d'altres llocs d'Europa, Amèrica i Àsia, tenen la seva primera associació. Més concretament, el dia 17 de desembre de 1999 es va crear l'associació Alcántara de mediadors interculturals, fruit de la iniciativa de persones vinculades a la formació i a la pràctica de la mediació intercultural en el marc del programa euro- 
peu Leonardo da Vinci i de les accions comunitàries Horizon i Integra. Així, des d'una òptica interpersonal, el mediador actuarà en els espais de relació entre professionals i usuaris en el que s'anomena «situació de triangle» $\mathrm{o}$ «posició tres", sense dependre de cap de les parts, oferint els seus coneixements, competències i actituds professionals a disposició de qui requereixi el seu servei.

\section{Bibliografia}

AEP Desenvolupament Comunitari / Andalucía Acoge (2002). Mediación intercultural. Una propuesta de formación. Madrid: Popular.

Besalú, X. (2002). Diversidad cultural y educación. Madrid: Síntesis. Teoría e Historia de la Educación.

GARRETA, J.; LlEVOT, N. (1999). «Los mediadores culturales: puente entre progenitores de las minorías étnicas y la institución escolar». Revista de Pedagogía Social. Monográfico de Educación Intercultural, 1, p. 95-114.

- (2003). El espejismo intercultural. La escuela de Cataluña ante la diversidad cultural. Madrid: CIDE, Ministerio de Educación, Cultura y Deporte.

Llevot, N. (2000). «Familias gitanas y centros educativos de Cataluña (España): la necesidad de una negociación». Rivista Internazionale di scienze dell'educazione, 282, p. 1.055-1.072.

- (2002). Els mediadors interculturals a les institucions educatives de Catalunya. Lleida: Departament de Pedagogia i Psicologia. Tesi doctoral.

MorerAS, J. (2001). «Temps d'assentament, temps d'integració? El col-lectiu marroquí a Catalunya». A MARQUÉS, S.; PALAUdÀRIAS, J.M. (eds.). Societats pluriculturals i educació: la interculturalitat com a resposta. Girona: Servei de Publicacions de la Universitat de Girona. Ajuntament de Girona, p. 105-122. Humanitats, 12.

SAN Román, T. (1994). La diferència inquietant. Velles i noves estratègies culturals dels gitanos. Barcelona: Fundació Serveis de Cultura Popular. Editorial Altafulla. Cultura Popular, 14.

SIX, J.F. (1997). Dinámica de la mediación. Barcelona: Paidós. 